\title{
The Impact of Parental Level of Income on Students' Academic Performance in High School in Japan
}

\author{
Chioma Henrietta Machebe*, Bernedeth N. Ezegbe, Joseph Onuoha \\ Department of Social Science Education, University of Nigeria, Nigeria
}

Copyright $\bigcirc 2017$ by authors, all rights reserved. Authors agree that this article remains permanently open access under the terms of the Creative Commons Attribution License 4.0 International License

\begin{abstract}
The socioeconomic status of a child parent impacts on the educational development and achievement of the child. This study evaluated the effect of socioeconomic status, specifically parents income and parents-child relationship on student's academic performance in Senior High School in Japan. Three hundred students of Senior High Schools in Osaka and Hyogo prefectures of Japan were randomly selected and used as the sample population. A well-structured questionnaire was used as an instrument for data collection to ascertain the effect of parent's income status and attitude on student's academic performance at school using a four point Likert scale methodology. Academics grade point of students in an examination was also used as the determinant of students' academic achievement. Results showed that greater academic achievement for a student is attained by those students from financially buoyant families (Mean $\pm \mathrm{SD}=2.97 \pm 0.88$, $X^{2}=11.991, \mathrm{P}=0.007$ ), however, $29.7 \%$ of students strongly disagree. More than half of respondents $(>50 \%)$ disagree that financial constraint determines the number of children that goes to school in low income families. Average exam grade (Mean $\pm \mathrm{SD}$ ) points for students from parents with high, medium and low-income status was 77.29 $\pm 13.1,77.9 \pm 23.3$ and $80.79 \pm 10.13$, respectively $(\mathrm{P}>0.05)$. In conclusion, our finding show parents involvement in children school activities matter most than the parent's financial status in uplifting the children academic performance in school. Our recommendation is that parents should always encourage their children and provide moral support as well for the child to be emotionally stable and have confidence in their academic pursuit to achieve excellence.
\end{abstract}

Keywords Socio-economic Status, Academic Achievement, High School, Family, Income

\section{Background/Objectives and Goals}

Parents play a pivotal role in the educational development of their children. Their involvement in the education of the children is of immense benefit to the child, the school and the parents as well [1]. A recent report [2], noted that children from parents that are more active in the process of imparting educational knowledge excel in their academic career and are often more productive in the society. With adequate care, tutelage and active participation of parents in the child's educational activities like monitoring of homework, participation in extracurricular activities, parent-teacher association, and other school related activities, the child is more likely to be courageous and as such do well at school. Earlier report [3] indicate that the extent and form of parental involvement are strongly influenced by family social class, maternal level of education, material deprivation, maternal psycho-social health and single parent status and, to a lesser degree, by family ethnicity. Parents who are more involved with their children's schooling become knowledgeable about school goals and procedures [4]. In addition, they communicate the importance of education to children and help children learn strategies to enhance their perceptions of competence and control over achievement outcomes [5]. Among the several parental factors that have been linked to their children academic achievements at school is the parent's level of income. According to Mayer, a casual observation is that the children of affluent parents are more likely to succeed in life than the children of poor parents probably because the rich parents spend more than poor parents on their children and these "investments" lead to better outcomes for their children [6]. If the situation is correct, the author also suggested that government can improve the life chances of poor children by providing families with the means to make the investments or by providing the investments directly in the form of schooling, health care, and other human capital inputs. It is not out of place to imagine that parental socio-economic background can have possible effects on the academic achievement of children in school [7]. When parents are financially capacitated, and also give moral support to the children by guiding their reading at home, the students perform better than their counterparts. Although it has been argued that the most accurate predictor of students' achievement is the 
extent to which the family is involved in the child's education, and not the family's level of income [8]. It is not clear if the situation is the same across developed and developing economies in the world. Japan is one of the leading economies in the world with a population of 126.88 million inhabitants as at December 1, 2015 (http://www.stat.go.jp/english/data/jinsui/tsuki/index.htm).

It is documented that prior to the $21^{\text {st }}$ century, Japanese students established great academic achievements that were admired worldwide [9]. These were evidenced in the student's excellent achievements in mathematics and sciences. Unfortunately, these huge academic achievements began to falter during the $21^{\text {st }}$ century and the reason calls for great concern and investigation. The aim of the present study was to evaluated the effect of socioeconomic status, specifically parents income and parents-child relationship on student's academic performance in Senior High School in Japan

\section{Methods}

Three hundred students of Senior High Schools in two prefectures namely Osaka and Hyogo were randomly selected and used as the sample population. A well-structured questionnaire was used as an instrument for data collection to ascertain the impact of parent's income status on student's academic performance in an examination. This questionnaire was designed using four point Likert scale (SA, strongly agree; A, agree; D, disagree; and SD, strongly disagree) methodology with 2.5 as average decision mark. Academics grade point of students in an examination was also used as one of the variables considered to denote students' academic achievement. The students opinion concerning parents income and their involvement in the student's academic activities vis-à-vis students' academic performance were ascertained by their responses to the questions; (i) parents who are professionals encourage their children academic activities; (ii) students from well rich families have all the learning materials needed for studies (iii) mothers who work all day don't have enough time to assist their children in out-of-school reading; (iv) financial constraint often determine how many children will go to school in low income earned families; and (v) greater academic achievements is attained by those from financially buoyant families. Data from the two prefectures was analyzed using chi-square statistic to test the null hypothesis and results presented as tables of frequencies and charts. Mean academic grade point of students (dependent variable) was compared using ANOVA with parent income status as an independent variable. The null hypotheses were tested at $5 \%$ level of significance.

\section{Results}

Results of the student's response of the effect of parental income on students' academic performance are shown in Table 1 and in Figures 1 to 5 [a \& b] (Hyogo and Osaka prefectures). Results showed that greater academic achievement for a student is attained by those students from financially buoyant families (Mean $\pm \mathrm{SD}=2.97 \pm 0.88$, $X^{2}=11.991, \mathrm{P}=0.007$ ), however, $29.7 \%$ of students strongly disagree. This was followed by parents' financial constraint as being the major determinant of the number of students that will go to school in low income earned families (Mean \pm SD $=2.50 \pm 0.87)$. Collectively for both prefectures, more than half $(54.0 \%)$ of the students agree that parents who are professionals encourage their children in academic activities (Figure 1b) while the other students have a contradictory opinion (46\%). About $44 \%$ of students from both prefectures agree that students from well rich families are provided with all the learning materials (figure $2 \mathrm{~b}$ ). In figure $3 \mathrm{~b}$, about $60 \%$ of students agree that mothers who work all day have less time to assist their children in out-of-school reading (Jukun). While about half (50\%) of students in Hyogo Prefecture disagree that financial constraint often determines how many child will go to school in low income earned families, $47 \%$ of the students in Osaka prefecture agree to the statement (Figure 4a). However, on average, greater number of students disagree that financial constraint poses a threat to a number of children that are allowed to go to school in low income earned families (Fig. 4b). In Figures $5 \mathrm{a}$ and $5 \mathrm{~b}$, the entire students disagree that greater academic achievements is attained by those from financially buoyant families. Average examination grade (Mean $\pm \mathrm{SD}$ ) points for students from parents with high, medium and low income status was $77.29 \pm 13.1,77.9 \pm 23.3$ and $80.79 \pm 10.13$, respectively (P > 0.05; Table 2) 
Table 1. Mean student's response on influence of parental level of income on students' academic performance

\begin{tabular}{|c|c|c|c|}
\hline Items & Mean & \pm SD & Decision \\
\hline $\begin{array}{l}\text { Parents who are professionals encourage their children's } \\
\text { academic activities. }\end{array}$ & 2.24 & 0.76 & $\mathrm{M}<2.5$ \\
\hline $\begin{array}{l}\text { Students from highly rich families have all the learning } \\
\text { materials needed for studies. }\end{array}$ & 2.14 & 0.82 & $\mathrm{M}<2.5$ \\
\hline $\begin{array}{l}\text { Mothers who work all days don't have enough time to } \\
\text { assist their children in out-of-school reading (Jukun). }\end{array}$ & 2.00 & 0.70 & $\mathrm{M}<2.5$ \\
\hline $\begin{array}{l}\text { Financial constraints often determine how many will go to } \\
\text { school in low income earned families. }\end{array}$ & 2.57 & 0.87 & $\mathrm{M}>2.5$ \\
\hline $\begin{array}{l}\text { Greater academic achievement is attained by those from } \\
\text { financially buoyant families. }\end{array}$ & 2.97 & 0.88 & $\mathrm{M}>2.5$ \\
\hline
\end{tabular}

Table 2. Effect of financial status of parents on students mean grade points of students (Mean $\pm \mathrm{SD}$ )

\begin{tabular}{|c|c|c|}
\hline Parents financial status & Students grade point (\%) & Probability \\
\hline High income & $77.29 \pm 13.10$ & $0.56^{\mathrm{NS}}$ \\
\hline Medium income & $77.90 \pm 23.30$ & \\
\hline Low income & $80.79 \pm 10.13$ & \\
\hline
\end{tabular}

NS -Not significant

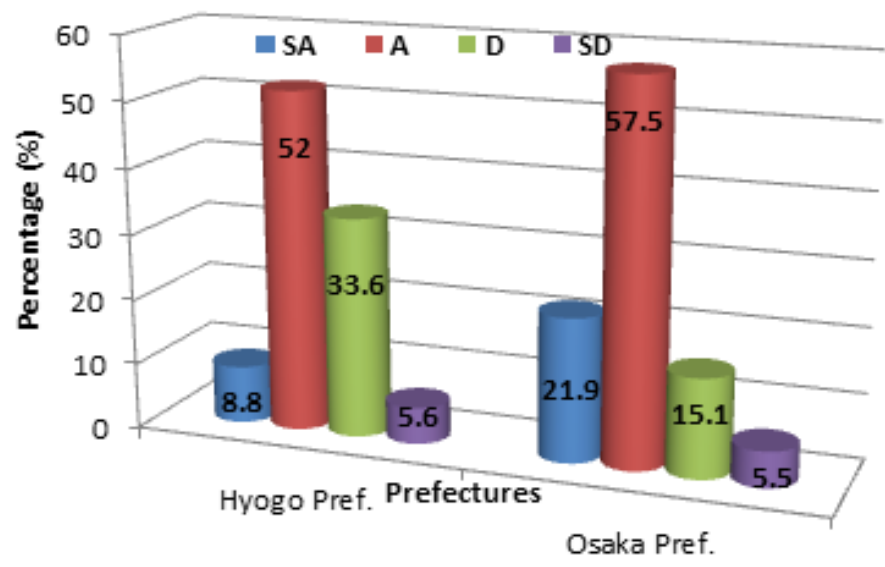

Figure 1a. Parents who are professionals encourage their children academic activities

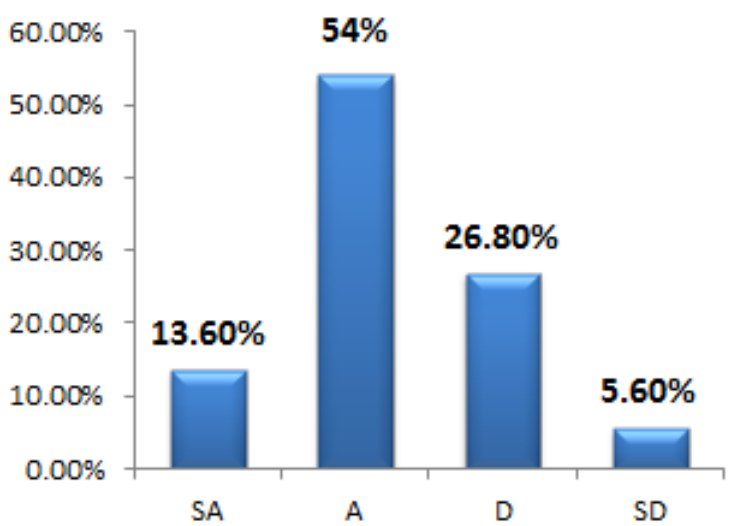

Figure 1b. Parents who are professionals encourage their children academic activities (Combined) 


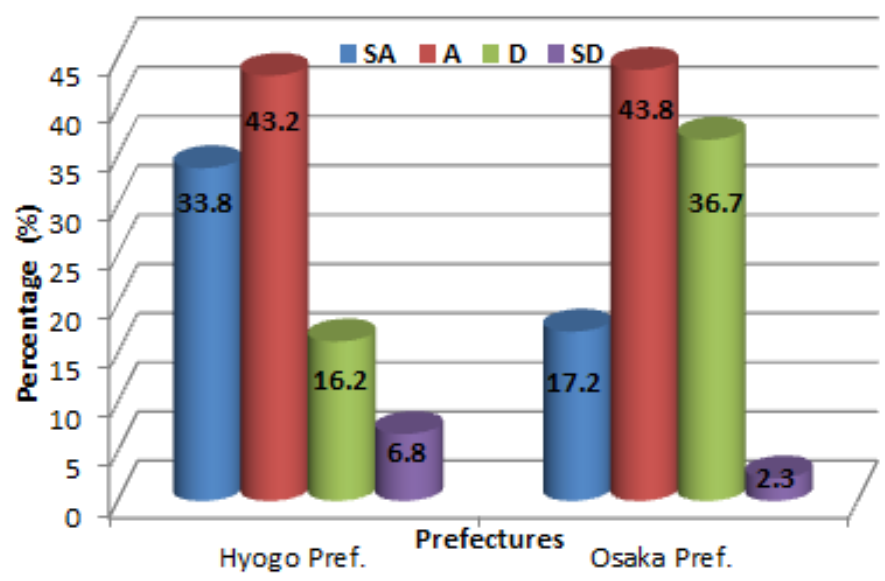

Figure 2a. Students from well rich families have all the learning materials needed for studies

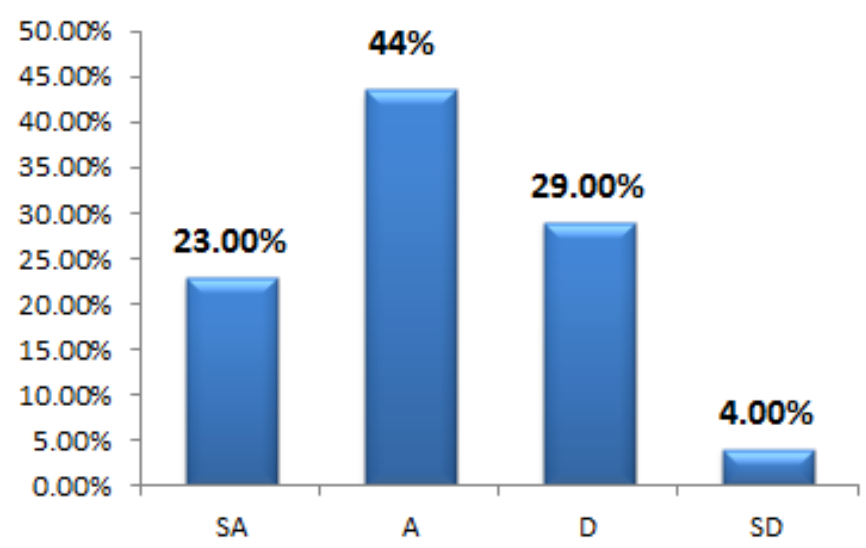

Figure 2b. Students from well rich families have all the learning materials needed for studies (Combined)

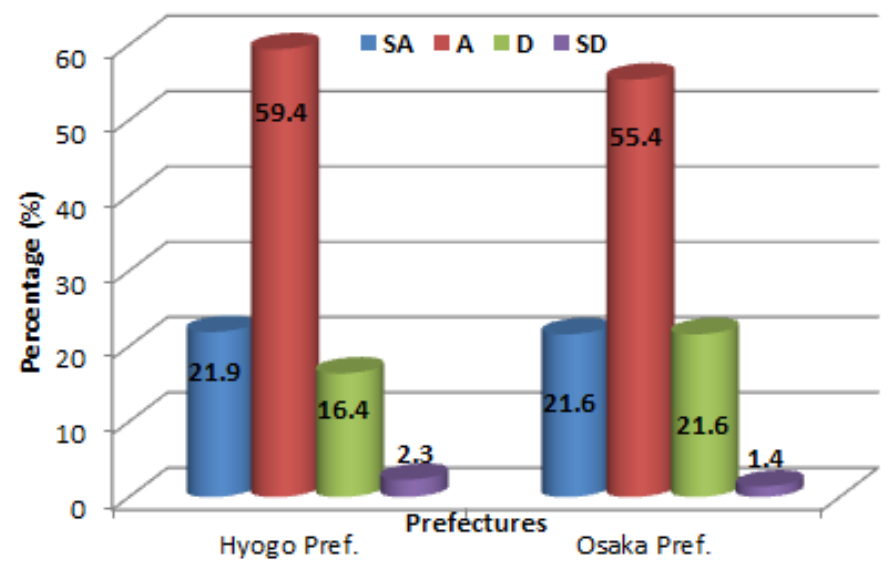

Figure 3a. Mothers who work all day don't have enough time to assist their children in out-of-school readings 


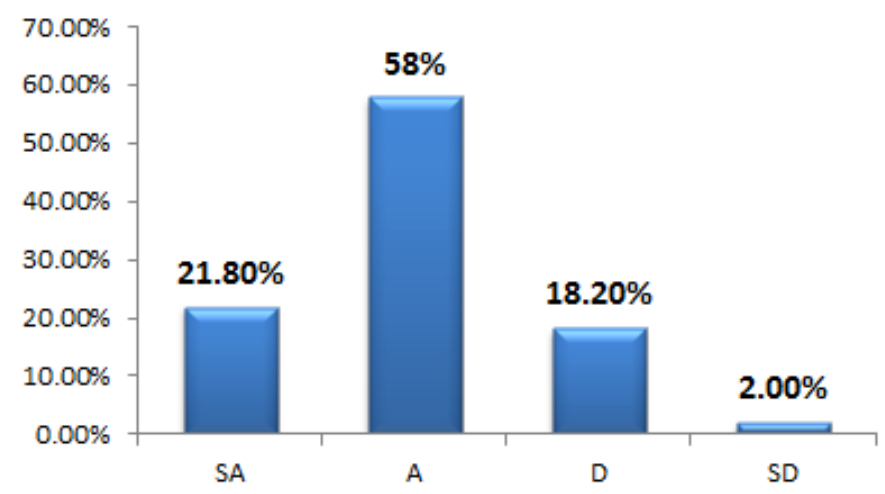

Figure 3b. Mothers who work all day don't have enough time to assist their children in out-of-school readings (Combined)

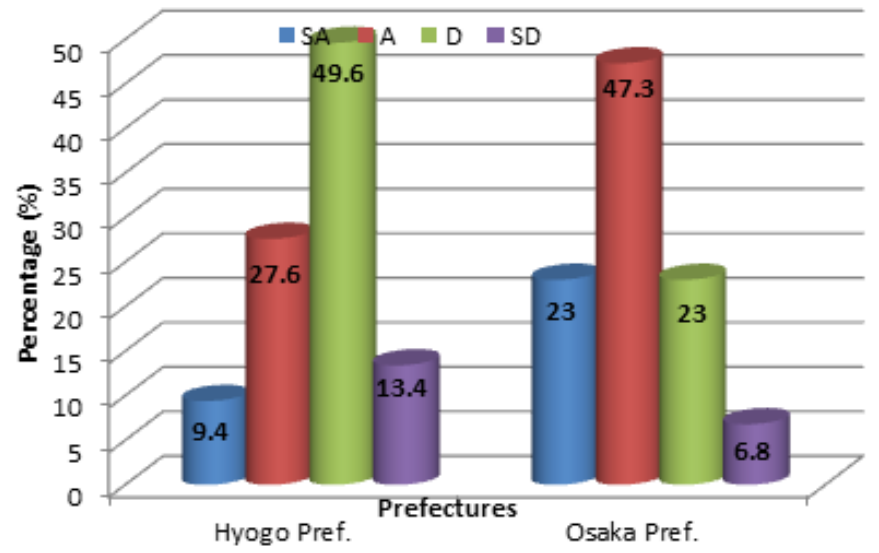

Figure 4a. Financial constraints often determine how many will go to school in low income earned families

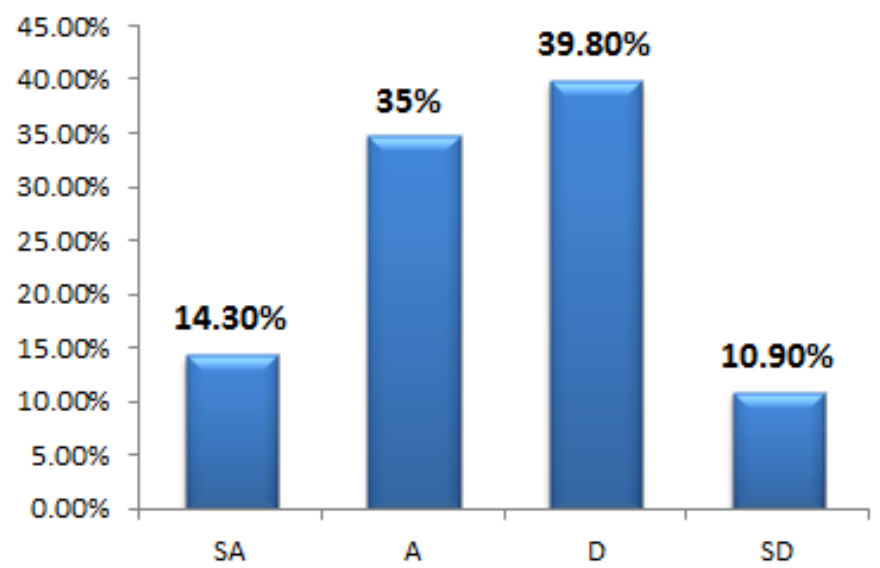

Figure 4b. Financial constraints often determine how many will go to school in low income earned families (Combined) 


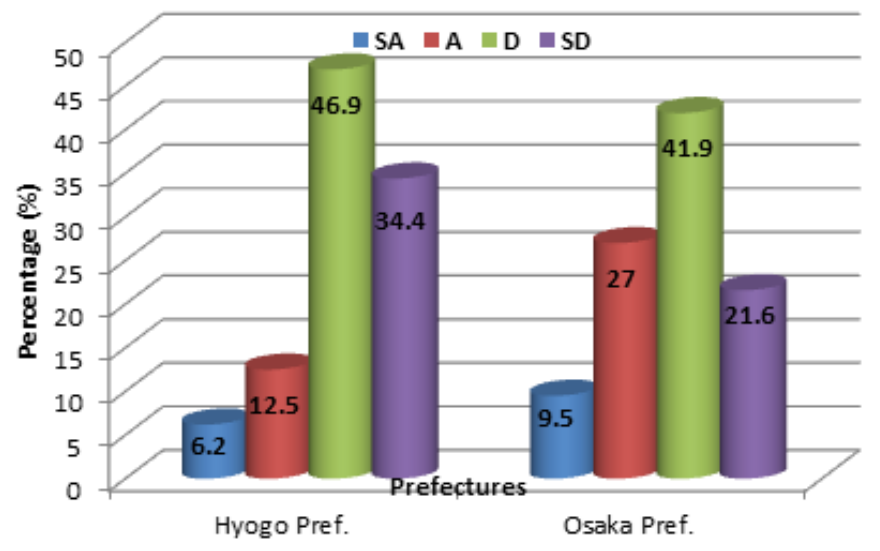

Figure 5a. Greater academic achievement is attained by those from financially buoyant families

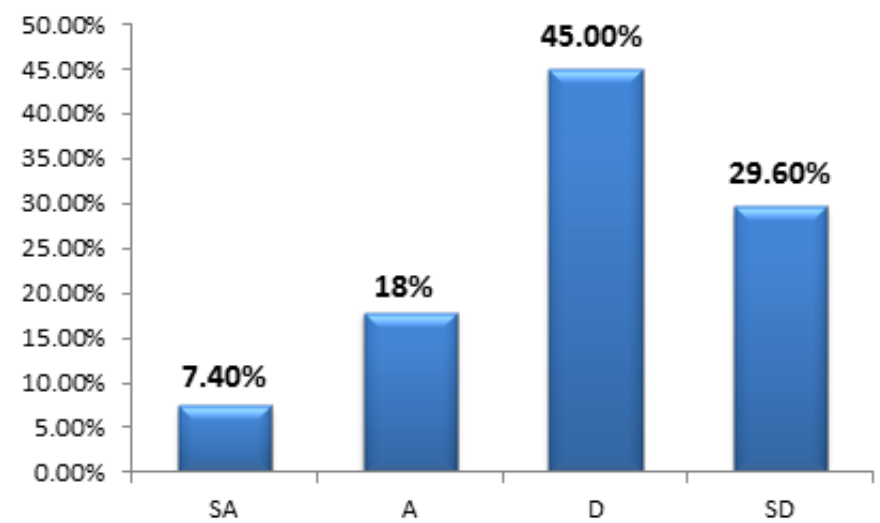

Figure 5b. Greater academic achievement is attained by those from financially buoyant families (Combined)

\section{Discussion}

The present findings have demonstrated that the income level of parents impacts on the academic achievements of the students. Also, parents have a critical role to play in improving the academic achievements of their children by providing the moral, financial and material support needed for their children to be encouraged to perform academically at school. This agrees with a report that parents have a key role to play in advancing the academic achievement of their children [3]. According to a report in the literature, parents who are more involved with their children's schooling become knowledgeable about school goals and procedures [4]. Indeed, other reports indicate that parents' education and family income positively influence the types of literacy-related materials, behavior in the home and parents and child relationship [10]. Our finding also shows that children from parents who are professionals have the capability and potential to perform better and improve in their academic pursuit probably because of the provision of learning materials needed by their children. On the other hand, it has been argued that in Japan such parents are sometimes too busy at work and spend less time on their children school activities [11]. This is in line with our present findings that mothers who work all day don't have enough time to assist their children in out-of-school readings (Jukun). For such mothers (especially single mothers) in Japan, finding the time and energy to help their kids keep up at school is often difficult and as such the academic performance of the child is hampered [11]. Reports in literature [12] have demonstrated that parental involvement is key in facilitating academic achievement of children. In Japan, it is known that a huge financial investment is required by parents to sustain their children in High School. As reported, one in six Japanese Children lives in poverty and the prospect of acquiring a good education is often hampered by their parent's inability to finance their schooling to High School [11]. On average, our finding show that Japan High school students disagree with the opinion that financial constraint is a determinant for knowing the number of children that will go to school in low income earned families (39\%). This may not be surprising since Japan has a compulsory education till the age of 15 which is relatively free during the period up to Junior High School in public schools [11]. In addition, although $45 \%$ of students in High School in the two prefectures disagree that a greater academic achievement is attained by students from financially buoyant families, an analysis of means of the sample population for the variable shows a mean of 2.97 which is greater than the 2.5 average point indicating that 
there is a greater chance that students from financially buoyant families are likely to attain greater academic achievements at school (Fig. 5b). Comparison of parent's financial status vis-à-vis the student's academic grade points (Table 2) showed no significant variation in the children mean percentage scores for the parents with high, medium and low-income levels. This may indicate that academic achievements of students in High Schools in Japan are relatively the same irrespective of whether their parent is in the high, medium and low-income levels. Repeated evidence [8] has confirmed that the most accurate predictor of student academic achievement is the extent to which the family is involved in the child's education, and not the family's level of income. Recent report indicate clearly that the efforts put forward by parents has a greater impact on their children's educational achievement than the effort expended by either teachers or the students themselves [13]. In Japan it is obvious that most married mothers stay out of work to take care of the home and children education and so are actively involved in the children school activities like reading stories aloud, meeting with teachers, playing with the child, etc. both at home and at school. This may account for the observed no difference in the academic performance of children based on variation in parent's income. Based on our present findings, it is therefore obvious that factors other than parent's financial status may contribute to the academic achievements of students in a High School in Japan. Some of these factors are mother's education level [14], the values and beliefs of the family and community [15], strong involvement of parents in the school process-inspection of homework, discussing school activities at home, attending school meetings and occasions, etc. $[13,16]$. In conclusion, therefore, our finding have shown that in Japan, parents involvement in children school activities matter most than the parent's financial status in uplifting the children academic performance in school. Our recommendation is that parents should always encourage their children and provide moral support as well for the child to be emotionally stable and have confidence in their academic pursuit to achieve excellence.

\section{REFERENCES}

[1] Campbell JR. Raising your child to be gifted: Successful parents speak: Brookline Books/Lumen Editions; 1995 Jan. 25 1995. $196 \mathrm{p}$.

[2] WaqasRafiq HM, Fatima T, Sohail MM, Saleem M, Ali Khan M. Parental Involvement and Academic Achievement; A
Study on Secondary School Students of Lahore, Pakistan. International Journal of Humanities and Social Science. 2013;3(8):209-23.

[3] Desforges C, Abouchaar A. The impact of parental involvement, parental support and family education on pupil achievement and adjustment: A literature review: DfES Publications Nottingham; 2003.

[4] Hill NE, Taylor LC. Parental school involvement and children's academic achievement pragmatics and issues. Current directions in psychological science. 2004;13(4):161-4.

[5] Lareau A. Home advantage: Social class and parental intervention in elementary education: Rowman \& Littlefield Publishers; 2000.

[6] Mayer SE. Revisiting an old question: how much does parental income affect child outcomes. Focus. 2010;27(2):21-6.

[7] Machebe $\mathrm{CH}$, Ifelunni $\mathrm{CO}$. Influence of Parental Socio-Economic Status on academic achievement of Students in Selected Schools in Nigeria: A case Study of Enugu State. Journal of Education and Practice. 2014;5(2):105-10.Kajita, E. (2006). The Decline in the Academic Level of Japanese Children and the Development of Educational Reform.

[8] Henderson AT, Berla N. A new generation of evidence: The family is crucial to student achievement: National Committee for Citizens in Education; 1994.

[9] Kajita E. The Decline in the Academic Level of Japanese Children and the Development of Educational Reform. 2006.

[10] Davis-Kean PE. The influence of parent education and family income on child achievement: the indirect role of parental expectations and the home environment. Journal of family psychology. 2005;19(2):294.

[11] Hagiwara Y, Reynolds I. In Japan, 1 in 6 children lives in poverty, putting education, future at stake. The Japan Times. 2015 September 10, 2015;Sect. National/Social Issues.

[12] Porumbu D, Necşoi DV. Relationship between Parental Involvement/Attitude and Children's School Achievements. Procedia-Social and Behavioral Sciences. 2013;76:706-10.

[13] Paul AM. Why Parenting Is More Important Than Schools. TIME online. 2012 Oct. 24, 2012.

[14] Lacour M, Tissington LD. The effects of poverty on academic achievement. Educational Research and Reviews. 2011;6(7):522-7.

[15] Shields PM. School and community influences on effective academic instructions. Berkeley, CA: MrCutchan Publishing Corp.; 1991.

[16] Bergeson T. Race, poverty, and academic achievement 2006 [Available from: http://www.doh.wa.gov/SBOH/ESS/documents/Race\&Povert y.pdf 